\title{
Model Pembelajaran Berbasis Permainan Engklek Dalam Upaya Pengembangan Karakter Sejak Usia Dini
}

\author{
Vina Gayu Buana ${ }^{1}$, Siti Uswatun Kasanah ${ }^{2}$ \\ Universitas Nahdlatul Ulama Blitar ${ }^{1,2}$ \\ vinagayu@unublitar.ac.id ${ }^{1}$, uswahunublitar@gmail.com²
}

\begin{tabular}{l}
\hline Tersedia Online di \\
\hline http://www.jurnal.unublitar.ac.id/ \\
index.php/briliant \\
\hline \\
\hline Sejarah Artikel \\
\hline Diterima pada 16 November 2018 \\
Disetuji pada 20 November 2018 \\
Dipublikasikan pada 20 \\
November 2018 Hal. 495-502 \\
\hline Kata Kunci: \\
\hline model pembelajaran, \\
pengembangan karakter, \\
permainan engklek \\
\hline DOI: \\
\hline http://dx.doi.org/10.28926/brilian \\
t.v3i3.254
\end{tabular}

\begin{abstract}
Abstrak: Penelitian ini merupakan penelitian pengembangan. Produk yang dikembangkan adalah model pembelajaran berbasis permainan engklek.Penelitian ini menggunakan model pengembangan Dick and Carrey dengan Sembilan langkah.Penelitian ini dilaksanakan di SD Negeri 6 Arjowilangun Kec.Kalipare.Subjek coba penelitian ini adalah siswa kelas IV Sekolah Dasar.Pengembangan produk dilakukan ujicoba dengan hasil yang dikonversikan pada tingkat kevalidan produk yaitu mendapat kriteria sangat valid dan dapat digunakan.Pembelajaran dengan menerapkan model berbasis permainan engklek ini dapat mengembangkan karakter siswa.
\end{abstract}

\section{PENDAHULUAN}

Beberapa tahun terakhir ini, pemerintah mencanangkan pendidikan karakter. Pendidikan karakter yang dimaksud harus terintegrasi dalam pembelajaran. Pada kenyataanya di sekolah-sekolah pengembangan karakter anak masih pada pengenalan-pengenalan karakter. Program pemerintah mengenai pendidikan karakter sebagai upaya pengimplementasian Nawacita Presiden. Kebijakan Presiden mengenai Penguatan Pendidikan Karakter (PPK) initerintegrasi dalam Gerakan Nasional Revolusi Mental (GNRM) yaitu perubahan cara berpikir, bersikap, dan bertindak lebih baik. Menurut Perpres No 87 tahun 2017tentang Penguatan Pendidikan Karakter dijelaskan bahwa nilai-nilai utama PPK yang dikembangkan adalah religious, nasionalis, mandiri, gotong royong, integritas. Nilai-nilai PPK diharapkan dapat dipraktikkan melalui sistem pendidikan nasional agar diketahui, dipahami, dan diterapkan di seluruh sendi kehidupan baik di sekolah maupun di masyarakat.

Pengembangan karakter pada anak perlu dilakukan sejak anak usia dini. Melalui pengembangan karakter sejak dini maka generasi masyarakat Indonesia akan menjadi manusia yang berkarakter sesuai dengan tujuan pendidikan yaitu melahirkan insan cerdas dan berkarakter kuat. Menurut Suparno (2015) ada beberapa model pendidikan karakter yaitu pendidikan karakter dilakukan secara holistik artinya melalui seluruh program sekolah, pelajaran, aturan sekolah, suasana sekolah, dan pendidikan orang tua di keluarga. Selain itu, pengembangan karakter pada anak dapat dilakukan melalui permainan-permainan tradisional. 
Permainan tradisional menurut Mulyani (2016) menyatakan bahwa di dalamnya terdapat nilai-nilai yang dapat ditanamkan, nilai-nilai tersebut antara lain rasa senang, bebas, rasa berteman, demokrasi, penuh tanggung jawab, rasa patuh, rasa saling membantu yang semuanya merupakan nilai-nilai yang sangat baik dan berguna dalam masyarakat. Hal ini sesuai dengan nilai-nilai pengembangan karakter yang diharapkan oleh pemerintah yang perlu ditanamkan sejak usia dini baik melalui lingkungan keluarga, sekolah, maupun masyarakat.

Di sekolah guru dapat mengembangkan karakter anak dengan berbagai cara, salah satu cara yaitu melalui pembelajaran dengan menerapkan model pembelajaran. Melalui pembelajaran guru dapat mengintegrasikan permainanpermainan untuk mengembangkan karakter siswa. Pada penelitian ini, peneliti mengembangkan model pembelajaran berbasis permainan engklek sebagai upaya dalam mengembangkan karakter anak sejak usia dini. Model pembelajaran engklek ini dilaksanakan dengan empat tahapan dalam pembelajaran, yaitu persiapan, pra permainan, permainan, dan penutup.

\section{METODE}

Penelitian ini menggunakan metode penelitian dan pengembangan. Model yang digunakan yaitu model Dick \& Carrey. Pemilihan model ini didasarkan beberapa alasan, yaitu (1) tahapan-tahapan model Dick \& Carrey sistematis dan praktis sehingga dapat dilakukan dengan baik dan menghasilkan produk yang layak, (2) dilakukan studi pendahuluan sehingga permasalahan yang terjadi dapat diketahui, (3) produk yang dikembangkan melalui proses uji coba untuk mengetahui tingkat kelayakan produk, (4) dilakukan revisi sehingga produk yang dikembangkan mendapatkan hasil yang sempurna. Berikut gambar tahapan model penelitian dan pengembangan Dick \& Carrey:

\section{Gambar 1}

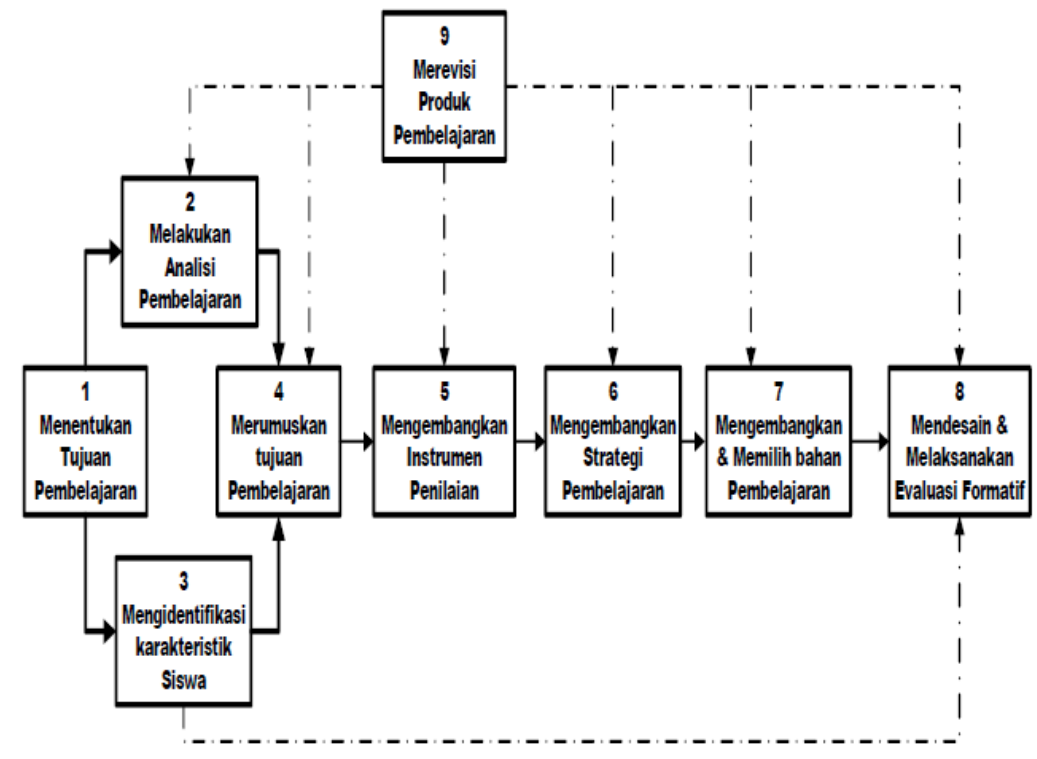

Langkah Desain Pembelajaran Model Dick \& Carey (Zulkipli 2016).

Penelitian ini dilaksanakan di SD Negeri 6 Arjowilangun Kec. Kalipare. Subjek penelitian yaitu validator ahli, guru sebagai pengguna dan siswa kelas IV Sekolah Dasar.Jenis data yang diperoleh pada penelitian ini yaitu kuantitatif dan kualitatif. Instrumen pengumpulan data yang digunakan yaitu angket validasi, angket pengguna (guru), lembar observasi, dan angket respon siswa. Teknik 
analisis data menggunakan teknik analisis kualitatif dan kuantitatif. Teknik analisis kualitatif digunakan untuk menganalisis data hasil saran/masukan serta hasil observasi. Teknik analisis kuantitatif digunakan untuk menganalisis data hasil dari angket respon guru dan angket respon siswa. Untuk mengetahui kepraktisan model pembelajaran, berikut rumus yang digunakan dalam mengukur kepraktisan model pembelajaran hasil dari angket guru dan siswa.

$$
V=\frac{T S e}{T S h}=100 \%
$$

Keterangan rumus:

$\mathrm{V}=$ Validasi

TSe $\quad=$ Total skor empirik

TSh $=$ Total skor maksimal

Sumber: Akbar, 2013:82

\section{HASIL}

Produk yang dikembangkan berupa model pembelajaran berbasis permainan engklek meliputi sintaks model pembelajaran berbasis permainan engklek, dilengkapi dengan jaring-jaring konsep KD, Rencana Pelaksanaan Pembelajaran (RPP), media, Lembar Kerja Siswa (LKS), dan penilaian autentik.

\section{Tabel 1 Hasil Validasi Ahli Pembelajaran}

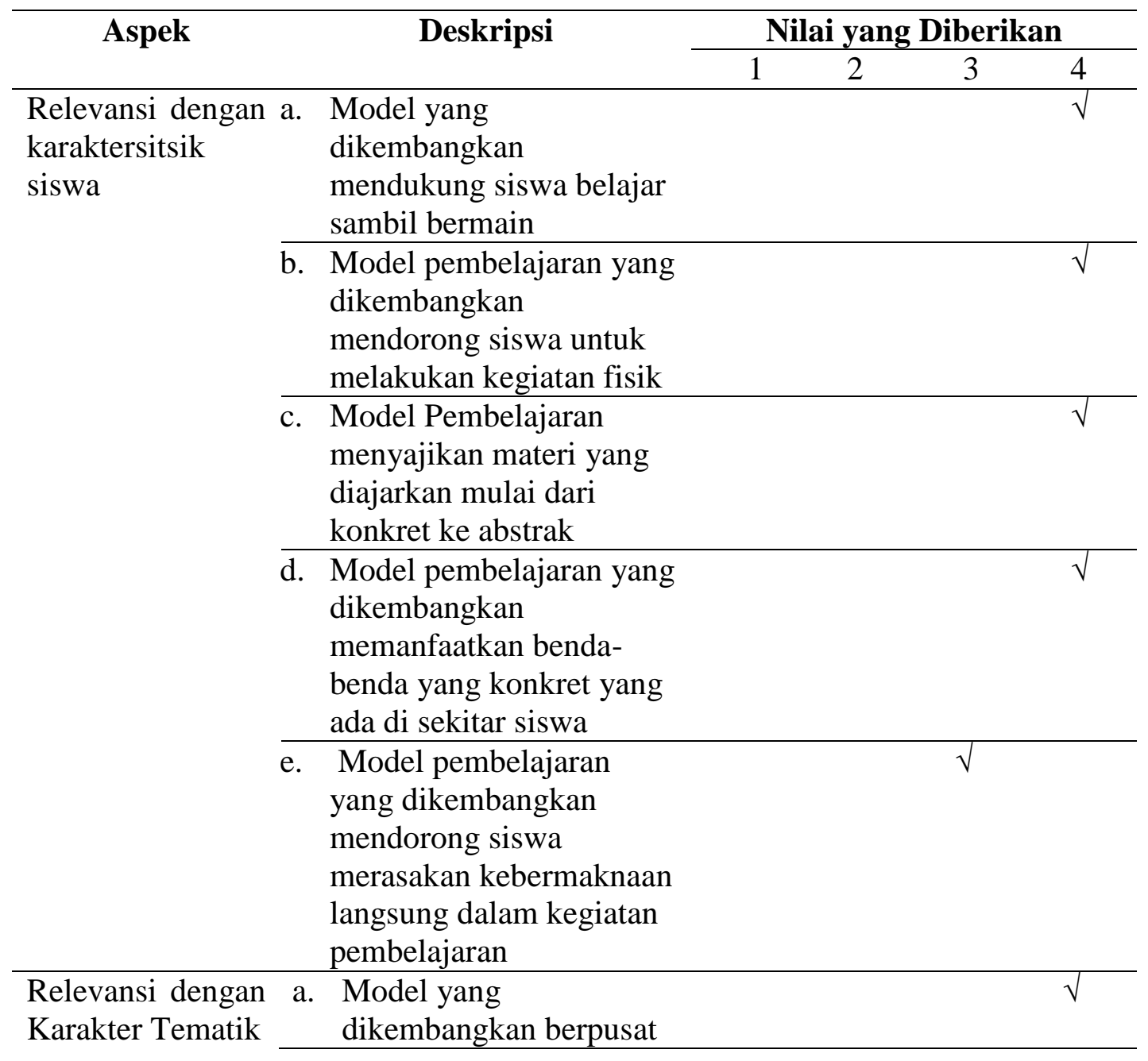




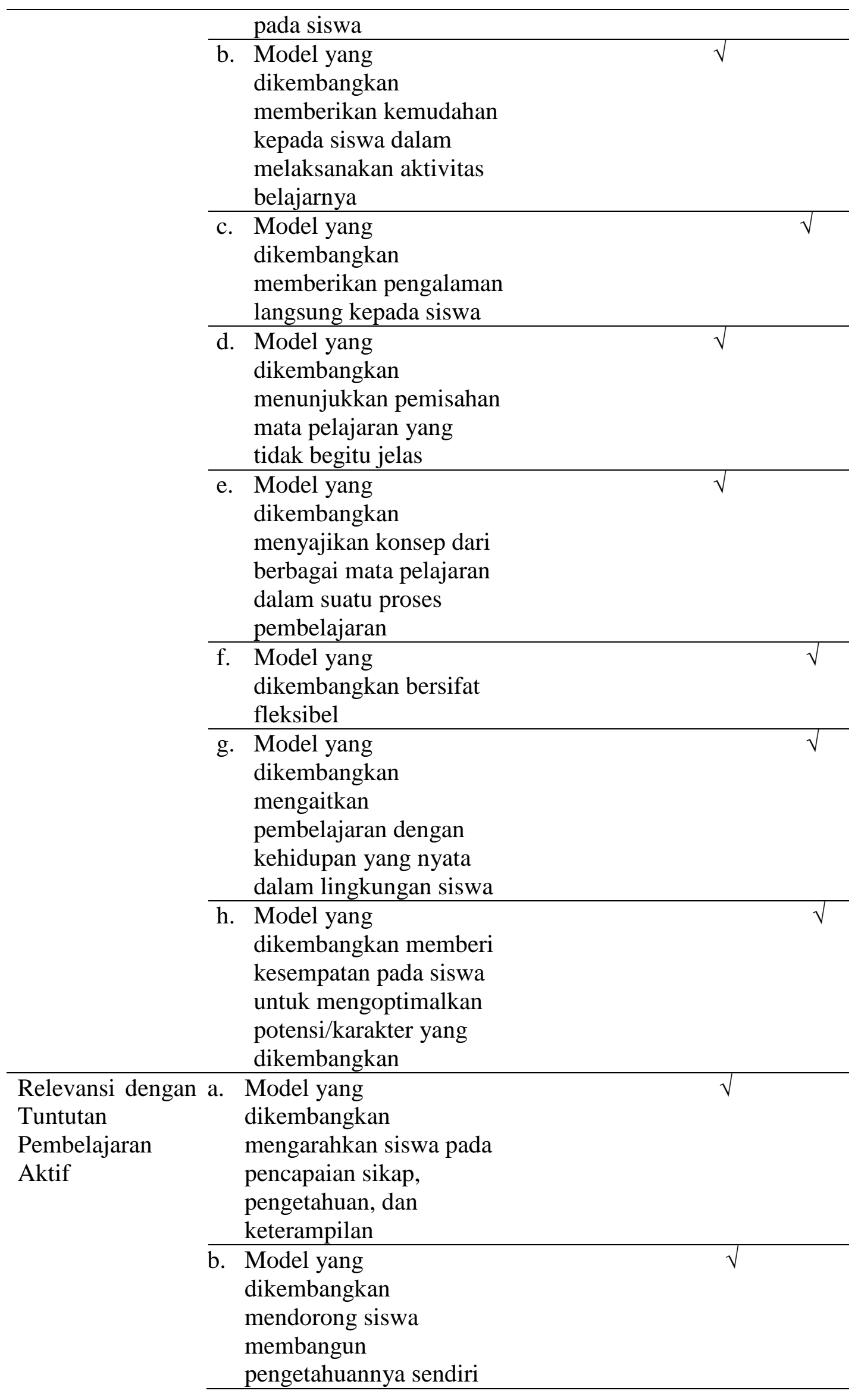




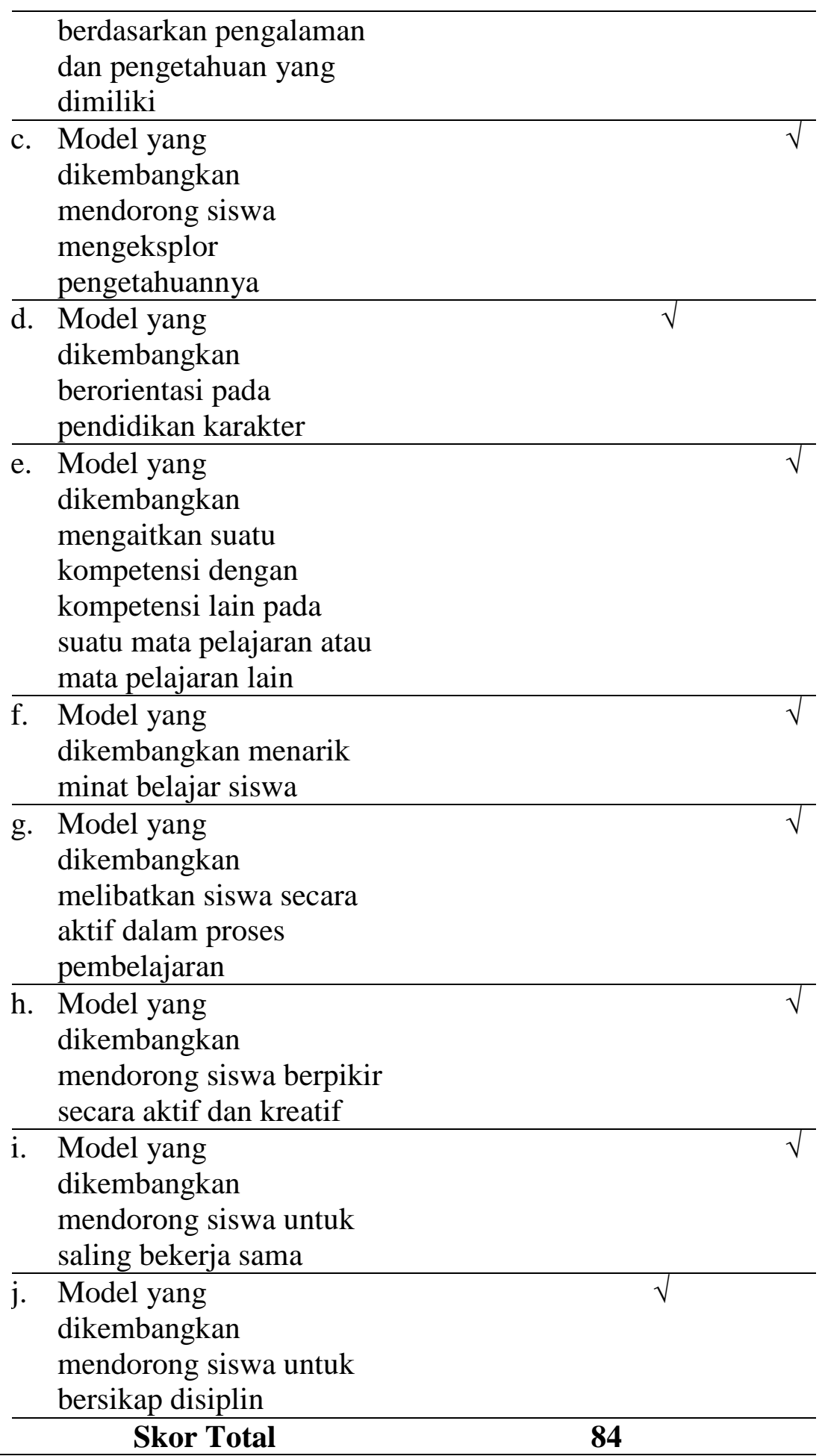

Sumber: Olahan peneliti

Pada Tabel 1 dapat dilihat bahwasanya hasil validasi produk oleh ahli pembelajaran diperoleh skor total 84 atau 91,30\%. Kemudian, hasil tersebut dikonversikan pada tingkat kevalidan produk, mendapat kriteria sangat valid dan dapat digunakan. Hasil ujicoba lapangan diperoleh skor 78 atau 97,5\%, dikonversikanpada tingkat kevalidan produk yaitu mendapat kriteria sangat praktis dan dapat digunakan. 
Hasil penelitian menggunakan instrumen penelitian catatan lapangan bahwasanya selama proses pembelajaran siswa nampak lebih disiplin dibuktikan dengan siswa masuk kelas tepat waktu, melaksanakan diskusi dengan baik dan menyelesaikan tugas tepat waktu, siswa tampak aktif dalam pembelajaran, siswa saling bekerja sama dengan siswa lain, dan lebih antusias mengikuti pembelajaran. Melalui karakter-karakter yang berkembang pada diri siswa ini diharapkan siswa menjadi manusia yang utuh artinya siswa yang bertaqwa kepada Tuhan Yang Maha Esa dan memiliki pengetahuan dan keterampilan yang baik, berbudi luhur, serta menjadi manusia yang demokratis dan bertanggung jawab. Dengan demikian untuk mewujudkan tujuan pendidikan nasional.

\section{PEMBAHASAN}

Penelitian dan pengembangan ini menghasilkan produk yang meliputi sintaks model pembelajaran berbasis permainan engklek, dilengkapi dengan jaring-jaring Kompetensi Dasar (KD), RPP, media, LKS, dan penilaian autentik.Desain produk yang dikembangkan lebih operasional sehingga dapat digunakan di kelas IV SD dengan menyesuaikan kebutuhan.Dalam hal pengembangan produk, peneliti memerhatikan beberapa perangkat yang digunakan dalam proses pembelajaran, sintaks model pembelajaran, jaring-jaring KD, RPP, media, LKS, dan penilaian autentik.

Model menurut Komarudin (2000) adalah suatu tipe atau desain, suatu deskripsi atau analogi yang digunakan untuk membantu proses visualisasi sesuatu yang tidak dapat dengan langsung diamati. Sedangkan menurut Joyce, dkk (1972:13) model pembelajaran adalah konsep yang mendeskripsikan berbagai macam aspek siswa dan menekankan pembelajaran lingkungan. Berbagai model pembelajaran yang dikembangkan Joyce bertujuan untuk meningkatkan kompetensi siswa agar tumbuh menjadi manusia yang memiliki kepribadian, sosial, dan akademis yang baik.

RPP yang dikembangkan menerapkan langkah-langkah pembelajaran berbasis permainan engklek. Guru sebelum melaksanakan pembelajaran menyusun RPP agar pembelajaran dapat berjalan dengan efektif dan efisien. Komponen RPP menurut Permendikbud no 22 Tahun 2016 terdiri atas: a) identitas sekolah yaitu nama satuan pendidikan; b) identitas mata pelajaran atau tema/subtema; c) kelas/semester; d) materi pokok; e) alokasi waktu; f) tujuan pembelajaran yang dirumuskan berdasarkan $\mathrm{KD}$; g) kompetensi dasar dan indikator pencapaian kompetensi; h) materi pembelajaran, memuat fakta, konsep, prinsip, dan prosedur yang relevan, dan ditulis dalam bentuk butir-butir sesuai dengan rumusan indikator ketercapaian kompetensi; i) metode pembelajaran, digunakan oleh pendidik untuk mewujudkan suasana belajar dan proses pembelajaran agar peserta didik mencapai KD yang disesuaikan dengan karakteristik peserta didik dan KD yang akan dicapai; j) media pembelajaran, berupa alat bantu proses pembelajaran untuk menyampaikan materi pelajaran; $\mathrm{k}$ ) sumber belajar, dapat berupa buku, media cetak dan elektronik, alam sekitar, atau sumber belajar lain yang relevan; 1) langkah-langkah pembelajaran dilakukan melalui tahapan pendahuluan, inti, dan penutup; dan $\mathrm{m}$ ) penilaian hasil pembelajaran.

Media digunakan sebagai sarana proses komunikasi dalam pembelajaran. Menurut Heinich dalam Sanjaya (2015) menyatakan bahwa media adalah media is 
a channel of communication. Derived from the Latin word for "between", the term refers "to anything that carries information between a source and a receiver. Dalam hal ini media sangat memiliki peran penting dalam pembelajaran, karena media merupakan saluran komunikasi antara sumber dan penerima. Perolehan pengetahuan siswa akan semakin abstrak apabila hanya disampaikan melalui bahasa verbal, hal ini memungkinkan terjadinya verbalisme artinya siswa hanya mengetahui tentang kata tanpa memahami dan mengerti maksud yang terkandung dalam kata tersebut, hal ini dapat menimbulkan kesalahan persepsi siswa. Oleh karena itu, pembelajaran sebaiknya menggunakan media agar dapat memberikan pengalaman siswa menjadi lebih konkret sehingga pesan yang disampaikan sesuai dengan harapan dan tujuan.

LKS merupakan salah satu sumber dalam belajar yang dapat dikembangkan oleh seorang guru sebagai fasilitator dalam pembelajaran. LKS juga merupakan media dalam penyampaian suatu pengetahuan. Hasil penelitian tindakan kelas yang dilakukan oleh Yusuf (2010) bahwa penggunaan LKS Interaktif berbasis komputer dapat meningkatkan hasil belajar siswa. Respon siswa terhadap penggunaan LKS Interaktif pada pembelajaran matematika adalah baik. Hasil belajar siswa dapat dilihat pada table 2 berikut ini.

Tabel 2 Nilai Rata-rata Hasil Belajar Siswa Menggunakan LKS Interaktif

\begin{tabular}{|l|l|c|}
\hline No. & \multicolumn{1}{|c|}{ Siklus } & Hasil \\
\hline 1 & Siklus I & 6,33 \\
\hline 2 & Siklus II & 6,90 \\
\hline
\end{tabular}

Penilaian Autentik merupakan penilaian yang menggunakan berbagai ukuran, metode, dan kriteria yang sesuai dengan karateristik dan esensi pengalaman belajar (Majid, 2017). Penilaian autentik bersifat holistik yang mecakup aspek sikap, kognitif, dan spikomotor, artinya dalam pelaksanaan pembelajaran guru menilai siswa dengan menggunakan berbagai macam teknik, misalnya: penilaian diri sendiri, penilaian antar teman, penilaian kinerja, penilaian proyek, dll.

Pembelajaran dengan mengintegrasikan permainan tradisional di dalamnya dapat mengembangkan karakter siswa, nampak dari hasil penelitian bahwasanya siswa lebih disiplin dan antusias mengikuti pembelajaran. Hal ini sesuai dengan pendapat Mulyani (2016) bahwa permainan-permaianan tradisional didalamnya terdapat nilai-nilai yang dapat ditanamkan kepada anak, antara lain rasa senang, bebas, berteman, demokrasi, tanggung jawab, rasa patuh, rasa saling membantu yang semuanya merupakan nilai-nilai yang sangat baik dan berguna dalam kehidupan masyarakat.

\section{KESIMPULAN}

Penelitian ini mengembangkan model pembelajaran berbasis permainan engklek. Produk yang dihasilkan berupa sintaks model pembelajaran berbasis permainan engklek, jaring-jaring KD, RPP, Media pembelajaran, LKS, dan penilaian autentik. Hasil uji coba diperoleh nilai 91,30\% dengan kriteria sangat valid dan dapat digunakan. Selain itu, selama proses pembelajaran siswa nampak lebih disiplin dibuktikan dengan siswa masuk kelas tepat waktu, melaksanakan diskusi dengan baik dan menyelesaikan tugas tepat waktu, siswa tampak aktif dalam pembelajaran, dan lebih antusias mengikuti pembelajaran. Melalui 
karakter-karakter yang berkembang pada diri siswa ini diharapkan siswa menjadi manusia yang utuh artinya siswa yang bertaqwa kepada Tuhan Yang Maha Esa dan memiliki pengetahuan dan keterampilan yang baik, berbudi luhur, serta menjadi manusia yang demokratis dan bertanggung jawab.

\section{SARAN}

Hasil penelitian ini disarankandikembangkan lebih lanjut dengan menggunakan desain eksperimen, pengembangan pada subtema lain, dan pengembangan untuk kelas lain/kelas yang berbeda.Penelitian ini dapat diimplementasikan di satuan pendidikan dengan skala yang lebih luas, dan akan lebih baik jika pengimplementasiannya sesuai dengan kondisi sekolah.

\section{DAFTAR RUJUKAN}

Akbar, S. 2013. Instrumen Perangkat Pembelajaran. Bandung: PT Remaja Rosdakarya.

Joyce, B. Weil, M. \& Calhoun, E. 1972.Model of Teaching.United States of America: Prentice-Hall, Inc.

Komarudin. 2000. Kamus Istilah Karya Tulis Ilmiah. Jakarta: Bumi Aksara.

Mulyani, N. Super Asyik Permainan Tradisional Anak Indonesia.Yogyakarta: Diva Press.

Perpres No 87 Tahun 2017 tentang Penguatan Pendidikan Karakter.

Sanjaya, W. 2015.Perencanaan dan Desain Sistem Pembelajaran. Jakarta: Prenadamedia Group.

Suparno, P. 2015. Pendidikan Karakter di Sekolah. Yogyakarta: PT Kanisius.

Yusuf, M. 2010. Peningkatkan Hasil Belajar Matematika Siswa melalui Lembar Kerja Siswa (LKS) Interaktif Berbasis Komputer di SMA Muhammadiyah 1 Palembang. Jurnal Pendidikan Matematika, 4 (2). pp. 34-44. ISSN 19780044

Zulkipli, dkk.2016. Pengembangan Modul Sistem Keamanan Jaringan Berbasis Simulasi Cisco.Jurnal Pendidikan Teori, Penelitian, dan Pengembangan 1 (3), hal 399-408 